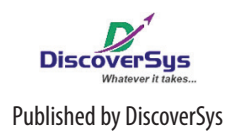

Published by DiscoverSys

\section{Where do we go with HIV pre-exposure prophylaxis in Indonesia?}

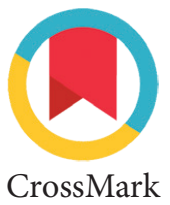

I Nyoman Sutarsa*

Department of Community and Preventive Medicine Faculty of Medicine Udayana University

*Correspondence to: I Nyoman Sutarsa, Department of Community and Preventive Medicine Faculty of Medicine Udayana University

sutarsa84@gmail.com
Mantled by discrimination and exclusion, HIV/ AIDS became a major epidemic of present-day globalization. Access to antiretroviral therapy (ART) and numerous preventative measures have resulted in reduced mortality and morbidity rates. ${ }^{1}$ However, the burden of disease associated with HIV infection remains tremendous. Total number of people living with HIV in 2016 were 36.7 million. ${ }^{1}$ Furthermore, the total people newly infected with HIV in 2016 were 1.8 million. Unfortunately, these global burdens disproportionally affect low and middle income countries - in particular Sub-Saharan Africa ${ }^{1}$ causing life expectancy to drop severely in those countries.

Even though several preventative measures have been deployed across regions in Indonesia, the epidemic of HIV-AIDS are still progressing. The cumulative reported HIV infections were 208,920 people, while for AIDS were 82,556 cases in $2016^{2}$ with fast-growing number of heterosexual and homosexual transmissions. Recent evidence suggest an increase prevalence of HIV among the men who have sex with men (MSM) population. Of 19,593 reported HIV infections in 2016, as many as $21.6 \%$ were found among the MSM population. ${ }^{2}$ Globally, HIV prevalence among the MSM population is estimated as being 13 times greater than the general population. ${ }^{3}$ The growing transmission among the MSM population have led global agenda towards biomedical prevention measures - including treatment as prevention and pre-exposure prophylaxis (PrEP).

In 2014 the WHO's Consolidated Guidelines recommended PrEP as an additional HIV prevention choice for gay men and other MSM in all epidemic settings and for other HIV-negative people in sero-discordant partnerships. ${ }^{3}$ In the same year, the Centre for Disease Control (CDC) also released a clinical guidance on the provision of Truvada (TFV), a combination of oral tenofovir disoproxil fumarate (TDF) $300 \mathrm{mg}$ and emtricitabine (FTC) 200mg, for MSM population. ${ }^{4}$ PrEP, an oral prophylaxis for HIV, is part of comprehensive HIV prevention services in which HIV negative people who are at high risk, consume ARV medication daily in attempt to lower their chances of becoming infected with HIV if they are exposed to it. ${ }^{3,4}$ Data from four major clinical trials in different population at risk ${ }^{5-8}$ showed that the efficacy of PrEP were varied between 44-75\%: 48.9\% reduction in HIV incidence among injecting drug users in Bangkok; ${ }^{6} 67 \%$ reduction in HIV incidence with TDF and $75 \%$ with TDF-FTC among sero-discordant heterosexual couples in Kenya and Uganda; ${ }^{5} 62.2 \%$ reduction in HIV incidence among sexually active heterosexual men and women in Botswana, ${ }^{8}$ and $44 \%$ reduction in the incidence of HIV with TDF-FTC among MSM.?

Despite the high efficacy to prevent HIV transmission from these trials, several questions remain to be answered: How can the national health systems be prepared for this new initiative? How will the national government cover the high cost of the drugs? How can risk compensation practices be prevented? How should the challenge of adherence be addressed? These questions must be taken into serious consideration prior to adoption of PrEP as a public health intervention in the Indonesia context.

The efficacy rates of PrEP are dependent on adherence rates. One trial among African women revealed that effects of PrEP cannot be observed because the adherence rate was very low. ${ }^{9}$ One study in urban Jakarta, Indonesia found that ART adherence in the last 3 months was only $77 \%{ }^{10}$ Issues around low adherence and the availability of drugs in the blood plasma ${ }^{11}$ must be addressed prior to adoption of PrEP as a public health intervention. Even though there is no sound evidence until recently, drug resistance should be considered when putting PrEP into practice, especially in a setting of low adherence rates to ARV medication such as in Indonesia.

PrEP may provide HIV risk reduction for unprotected sex, especially among the MSM population, ${ }^{12}$ however risk compensation practices should also guide the decision around adopting PrEP as a public health intervention. A reduced perception of risk after taking PrEP might lead to more frequent risk taking behaviour. For example, implementation of PrEP might reduce condom use resulting in higher risk for other STIs transmission. Further studies are required to assess individual and community risk compensation practices prior to implementing PrEP as a public health intervention.

From a health system perspective, costs to implement PrEP need to take into account before adopting PrEP as a public health intervention. The current per capita expenditure on health for 
Indonesia (USD \$16), low purchasing power of the national health systems, and the fact that PrEP drugs are not included under the national health insurance scheme should carefully guide the decision on adopting PrEP as a public health intervention. As PrEP is a lifetime medication, additional costs associated with monitoring of side effects, blood plasma drugs level, HIV test, and other STIs test should also be added. A projection in Leshoto reported that PrEP is more costly not only due to the drugs, but also associated with ongoing contact between the population and health providers as well as increased level of surveillance. ${ }^{13}$

Implementation of PrEP as a public health intervention requires an effective health system structures to ensure effective implementation and equal access to such an expensive program. Some experts suggest that PrEP can be put into practice in some settings, ${ }^{14,15}$ however in the context of developing countries including Indonesia, a substantial budget is required to implement PrEP. Acceptability of PrEP must also be further investigated especially among the MSM population. Other health service delivery challenges must also be taken into account, for example existing facilities for monitoring side effects and the availability of drugs in blood plasma, as well as the availability of adequate and trained human resources.

PrEP is an effective additional prevention strategy at trial settings. Decision to adopt PrEP as a public health intervention must be made based on the need and capacity of current systems. Instead of allocating substantial resources for PrEP, the limited resources could be wisely allocated to scale-up the existing prevention strategies including access to ART, as well as to ensure equality of access of people to full-range of HIV prevention and treatment measures.

\section{REFERENCES}

1. UNAIDS. UNAIDS Data 2017: Joint united nations program on HIV/AIDS; 2017.

2. Ministry of Health of Indonesia. Laporan situasi perkembangan HIV-AIDS dan PIMS di Indonesia: April-Juni 2016 [Situational analysis report on HIV-AIDS and STIs epidemic in Indonesia: April - June 2016]. Jakarta: Ministry of Health of Indonesia; 2016.
3. WHO. Consolidated guidelines on HIV prevention, treatment, and care for key populations. Geneva: World Health Organisation; 2014.

4. CDC. Pre-exposure prophylaxis for the prevention of HIV infection in the United States: 2014 Clinical Practice Guideline: Centre for Disease Control, Department of Health and Human Services USA; 2014.

5. Baeten JM, Donnell D, Ndase P, Mugo NR, Campbell JD, Wangisi J, et al. Antiretroviral prophylaxis for HIV prevention in heterosexual men and women. The New England Journal of Medicine. 2012; 367(5): 3 99-410.

6. Choopanya K, Martin M, Suntharasamai P, Sangkum U, Mock PA, Leethochawalit M, et al. Antiretroviral prophylaxis for HIV infection in injecting drug users in Bangkok, Thailand (the Bangkok Tenofovir Study): a randomised, double-blind, placebo-controlled phase 3 trial. Lancet. 2013; 381: 2083-90.

7. Grant RM, Lama JR, Anderson PL, McMahan V, Liu AY, Vargas L, et al. Preexposure chemoprophylaxis for HIV prevention in men who have sex with men. The New England Journal of Medicine. 2010; 363(27): 2587-99.

8. Thigpen MC, Kebaabetswe PM, Paxton LA, Smith DK, Rose CE, Segolodi TM, et al. Antiretroviral preexposure prophylaxis for heterosexual HIV transmission in Botswana. The New England Journal of Medicine. 2012; 367(5): 423-34.

9. Damme LV, Corneli A, Ahmed K, Agot K, Lombaard J, Kapiga S, et al. Preexposure prophylaxis for HIV infection among african women. The New England Journal of Medicine. 2012; 367(5): 411-22.

10. Weaver ERN, Pane M, Wandra T, Windiyaningsih C, Herlina, Samaan G. Factors that influence adherence to antiretroviral treatment in an urban population, Jakarta, Indonesia. PLoS One. 2014; 9(9): e107543.

11. Cohen MS, Baden LR. Preexposure prophylaxis for HIV Where do we go from here? The New England Journal of Medicine. 2012; 367(5): 459-61.

12. Haire B. Considering pre-exposure prophylaxis: do the pros outweigh the cons as an HIV prevention strategy? LGBT Health. 2014; 1(4): 253-5.

13. Kenworthy NJ, Bulled N. From modelling to morals: imagining the future of HIV PrEP in Leshoto. Developing World Bioethics. 2013; 13(2): 70-8.

14. Veloso VG, Mesquita F, Grinsztejn B. Pre-exposure prophylaxis for men and transgender women who have sex with men in Brazil: opportunities and challenges. Journal of the International AIDS Society. 2015; 18(3): 20010.

15. Bourne A, Cassolato M, Wei CKT, Wang B, Pang J, $\mathrm{Lim} \mathrm{SH}$, et al. Willingness to use pre-exposure prophylaxis (PrEP) for HIV prevention among men who have sex with men (MSM) in Malaysia: findings from a qualitative study. Journal of the International AIDS Society. 2017; 20: 21899.

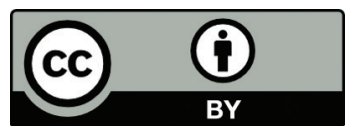

This work is licensed under a Creative Commons Attribution 